2011-8

\title{
Monofilar Spiral Slot Antenna for Dual-Frequency Dual-Sense Circular Polarization
}

\author{
Xiulong Bao \\ Technological University Dublin, xiulong.bao@tudublin.ie \\ Max Ammann \\ Technological University Dublin, max.ammann@tudublin.ie
}

Follow this and additional works at: https://arrow.tudublin.ie/ahfrcart

Part of the Systems and Communications Commons

\section{Recommended Citation \\ Bao, X.L., \& Ammann, M.J. (2011) Monofilar Spiral Slot Antenna for Dual-Frequency Dual-Sense Circular Polarization, Transactions on Antennas \& Propagation, IEEE, vol. 59, no. 8, pp. 3061-3065, 08/2011. doi:10.1109/TAP.2011.2158964}

This Article is brought to you for free and open access by the Antenna \& High Frequency Research Centre at ARROW@TU Dublin. It has been accepted for inclusion in Articles by an authorized administrator of ARROW@TU Dublin. For more information, please contact arrow.admin@tudublin.ie, aisling.coyne@tudublin.ie, gerard.connolly@tudublin.ie. Funder: Science Foundation Ireland

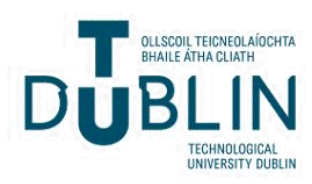




\title{
Monofilar Spiral Slot Antenna for Dual-Frequency Dual-Sense Circular Polarization
}

\author{
Xiulong Bao, Member, IEEE, Max J. Ammann, Senior Member, IEEE
}

\begin{abstract}
A dual-band antenna with right-hand circular polarization for the first frequency and the counter polarization at the second frequency is realized with compact printed spiral slots. The coupled spiral slots are fed by a $50 \Omega$ microstrip line. Dual-sense circularly-polarized performance is achieved by realizing oppositely-directed current rotation for the two frequency bands. A parametric study shows that the additional slot significantly improves the bandwidth for both frequency bands. Measured results show that the fractional impedance bandwidth is greater than $18 \%$ for both bands. The $3 \mathrm{~dB}$ axial-ratio bandwidths are $4.5 \%$ and $3.5 \%$ for the RHCP and LHCP bands, respectively.
\end{abstract}

Index Terms - Dual Frequency, Dual Circular Polarization, Spiral Slot Antenna

\section{INTRODUCTION}

C IRCUlarly-POLARIZED (CP) antennas have been used for decades for satellite communications and positioning systems and more recently for wireless communication and sensor system applications. This is due to advantages including immunity to Faraday rotation, mitigation of multipath propagation effects and reduced antenna orientation constraints. Many investigations have been carried out on broadbanding [1], miniaturization [2] and multiband operation of CP antennas [3]. Dual sense CP antennas have been also investigated [4], [5]. These antennas find application where dual-band reception of both RHCP and LHCP signals are required, such as in multimode GPS and Satellite Digital Audio Broadcast Systems. Other applications include wireless communications where dual CP offers improved isolation between channels compared to co-polarized systems.

It is well known that the spiral structure can achieve $\mathrm{CP}$ characteristics [6] and $\mathrm{CP}$ spiral slot antennas have been reported [7]. Double, triple and quadruple-arm spiral structures have realized wider CP bandwidths [8]-[10] and dual frequency spiral antennas [11] have been realized. Furthermore a single-arm spiral strip antenna has been reported which can achieve dual-sense CP by feeding either at the inner or outer spiral end [12].

In this paper, the first dual-frequency dual-sense CP performance from a spiral slot geometry is realized using a

\footnotetext{
Manuscript received September 9, 2010. This publication has emanated from research conducted with the financial support of Science Foundation Ireland under Grant Number 09/SIRG/11644.

Xiulong. Bao and Max J. Ammann are with the Antenna and High Frequency Research Centre, Dublin Institute of Technology, Dublin 8, Ireland (email:ammann@ieee.org)
}

single microstrip feed. Furthermore, the introduction of an additional embedded spiral slot is shown to improve the axial-ratio (AR) bandwidth.

\section{Configuration of the Proposed Spiral Slot ANTENNAS}

\section{A. The Single Spiral Slot Antenna}

The spiral slot antenna is initially investigated without the embedded slot for simplicity and can be seen in Fig. 1a-c. The slot is approximately one and a quarter turns long and the radius sequentially increases with movement of the origin point each quarter turn. The starting values are outer radius $R_{l}$ and origin $O_{1}$. The second quadrant has an outer radius $R_{2}$ and origin $O_{2}$. The $3^{\text {rd }}, 4^{\text {th }}$ and subsequent quadrants have radii $R_{3}, R_{4}$ and $R_{5}$ with origins $O_{3} O_{4}$ and $O_{1}$, respectively. The slot maintains the same width $W_{l}$. In order to improve matching for both bands, the microstrip feedline width is stepped using lengths $L_{s l}, L_{s 2}$ and widths $W_{s l}$ and $W_{s 2}$ as shown in Fig. 1a. Magnetic currents are excited on the slot, travelling out from the microstrip feed in opposite directions, establishing dual $\mathrm{CP}$ characteristics. The slot perimeter length corresponds approximately to one and two guided wavelengths for the first and second operating frequencies, respectively.

\section{B. The Dual Spiral Slot Antenna}

Fig. 1d shows the dual spiral slot antenna geometry, which consists of the above described spiral antenna with an additional smaller embedded concentric spiral slot. The smaller slot has outer radius values $r_{i}(i=[1,5])$ and origin points $O_{i}$, $(i=1,2,3,4,1)$. The separation between the inner and outer spiral slot is $S_{c}$. The slot width is $W_{2}$.

\section{DESIGN PROCEDURE}

\section{A. Single Spiral Slot Antenna}

Firstly, the groundplane size was chosen to be $100 \mathrm{~mm} \times 100 \mathrm{~mm}$ which is approximately a half of a free space wavelength at the lowest operating frequency. The antenna matching is sensitive to this dimension and it was chosen for best matching for both bands. A low-cost substrate with $\varepsilon_{\mathrm{r}}=3.5, \tan \delta=0.0018$ and $1.57 \mathrm{~mm}$ of thickness was chosen.

Secondly, the $50 \Omega$ microstrip feedline $\left(W_{s 2}=3.0 \mathrm{~mm}\right)$ is stepped to $W_{s I}=1 \mathrm{~mm}(95 \Omega)$ for good matching to the higher impedance slot.

Thirdly, the slot radius is increased to generate the spiral geometry. The origin $O_{l}$ is positioned centrally in the board 
and an origin offset of $O_{1} O_{2}=O_{3} O_{4}=2 \mathrm{~mm}$ is used.

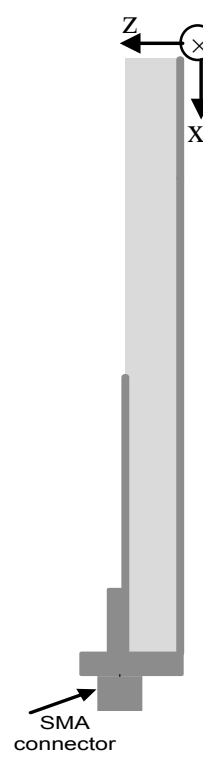

(b)

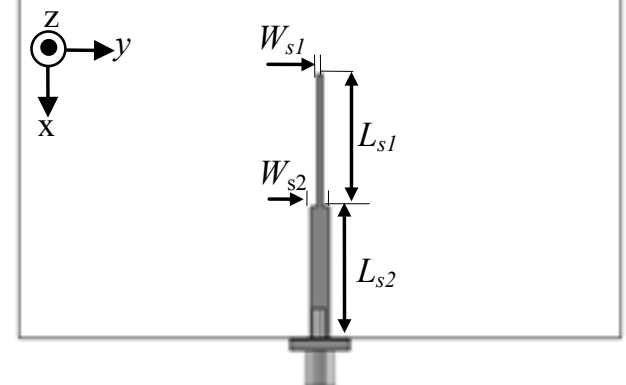

(a)

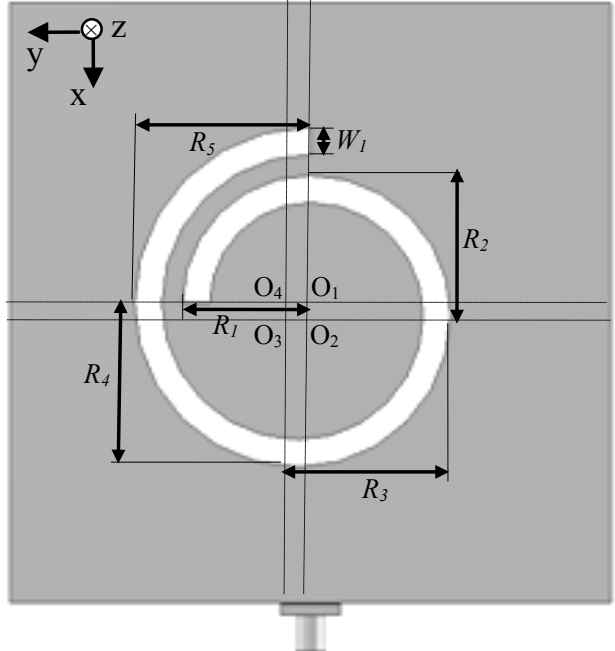

$\overline{(c)}$

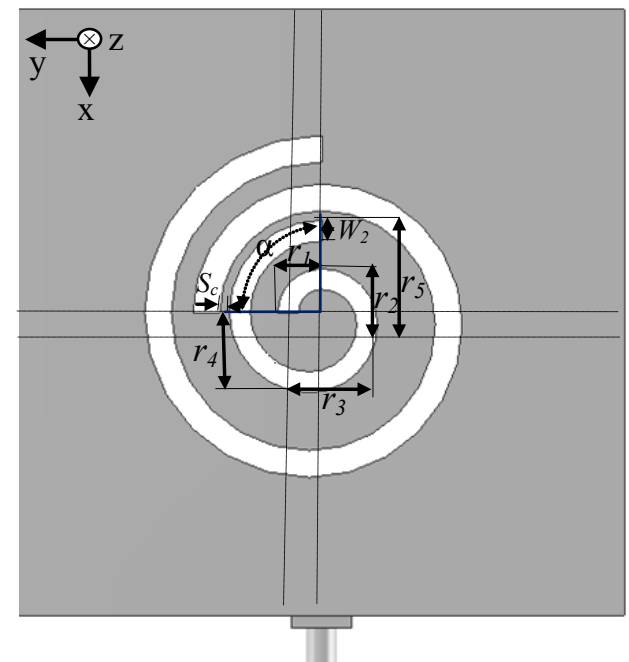

(d)

Fig. 1. Geometry of the proposed spiral slot antennas (a) Feedline (b) Profile (c) Single spiral slot antenna (d) Dual-slot spiral slot antenna
The starting slot radius $R_{l}$ is chosen to be approximately $1 / 8$ of a guided wavelength $\lambda_{g}$ for the lowest frequency. Subsequent radii increase by $2 \mathrm{~mm}$ per quarter-circle which was found to provide best axial-ratio (AR) and matching.

The operating frequencies, radiation patterns and AR beamwidth are dependent on the slot perimeter. The radiation patterns for a single-arm rectangular spiral antenna are dependent on the peripheral length of the spiral [13]. For peripheral lengths between $\lambda_{g}$ and $2 \lambda_{g}$, the radiation patterns are axial, whereas the pattern tilts off axis for lengths between $2 \lambda_{g}$ and $3 \lambda_{g}$.

In this case, the slot perimeter length approximates $\lambda_{g}$ for the low frequency and a wide AR beamwidth is realized, whereas the slot length is about $2 \lambda_{g}$ for the higher frequency and a narrow beamwidth is observed.

In order to investigate the mechanism for dual circular-polarization for the single spiral slot antenna, the current distribution for both low and high frequencies are shown in Fig. 2 (a) and (b).

It can be seen from Fig. 2 (a) that the resonant frequency for the low frequency (RHCP) is mainly determined by the outside length $\left(1 / 2 \times \pi \times\left(R_{4}+R_{5}\right)\right)$, which is the circumference length from the feedpoint to the endpoint of the outside spiral slot and approximates a half of the guided wavelength. The full slot perimeter is about one guided wavelength at this frequency. As seen from Fig. 2 (b), the resonant frequency of the high frequency (LHCP) is mainly determined by the inner length $\left(1 / 2 \times \pi \times\left(R_{1}+R_{2}+R_{3}\right)\right)$ which is the circumference length from the feedpoint to the endpoint of the inner spiral slot. This length in combination with some additional electrical lengthening due to coupling with the outside spiral approximates $\lambda_{g}$ at the centre frequency for LHCP. The full slot perimeter is about $2 \lambda_{g}$ at this frequency.

The low frequency current distribution shows the current traveling in an anti-clockwise fashion when viewed from the $+Z$ direction, leading to the radiation of a RHCP wave. The high frequency current travels in the opposite direction yielding a LHCP wave in the $+Z$ direction.

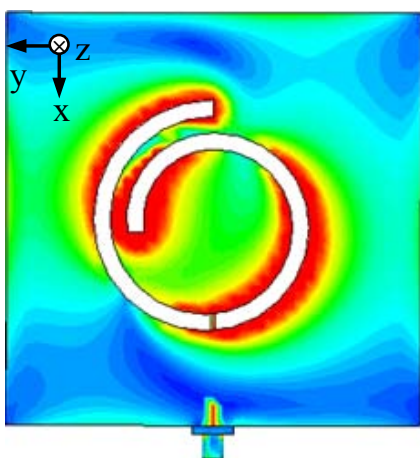

(a) low frequency

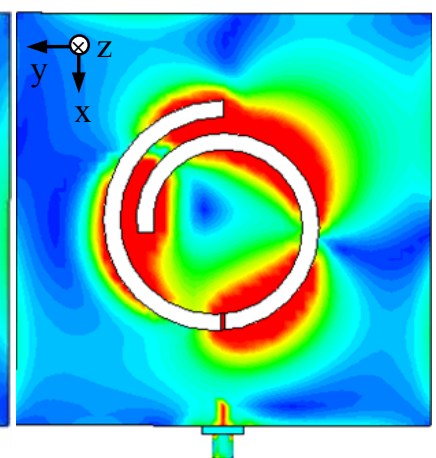

(b) high frequency
Fig. 2. Surface current distributions for low and high bands

\section{B. Dual Spiral Slot Antenna}

Based on the investigation in this paper, dual-sense $\mathrm{CP}$ characteristics can be achieved by the single spiral slot antenna, but with very narrow AR bandwidth for the lower frequency band. Hence, the introduction of the second embedded spiral 
slot is proposed to enhance matching and AR bandwidth for the low frequency band.

The smaller spiral slot is strongly coupled to the larger spiral slot for the first frequency band which significantly improves impedance matching and axial ratio. Furthermore, the smaller concentric spiral has little effect on the second band because of the relatively weak coupling at these frequencies. The slot perimeter length of the outer spiral slot is now approximately $1.17 \lambda_{g}$ at the lower frequency, whereas for the upper frequency, it remains at approximately $2 \lambda_{g}$.

\section{Comparison of $S_{11}$ and Axial Ratio for the Single and Dual Spiral Slot Antennas}

The parameters for the single and dual spiral slots are listed in Table 1.

Table 1 Parameters of the single and dual spiral slot antenna

\begin{tabular}{ccc}
\hline \hline Parameters & $\begin{array}{c}\text { Single Spiral Antenna } \\
(\mathrm{mm})\end{array}$ & $\begin{array}{c}\text { Dual Spiral Antenna } \\
(\mathrm{mm})\end{array}$ \\
\hline$R_{1} / r_{1}$ & 21 & $21 / 7$ \\
$R_{2} / r_{2}$ & 23 & $23 / 9$ \\
$R_{3} / r_{3}$ & 25 & $25 / 11$ \\
$R_{4} / R_{4}$ & 27 & $27 / 13$ \\
$R_{5} / R_{5}$ & 29 & $29 / 15$ \\
$L_{S 1}$ & 22 & 22 \\
$L_{S 2}$ & 22 & 22 \\
$W_{S 1}$ & 1 & 1 \\
$W_{S 2}$ & 3 & 3 \\
$W_{1}$ & 4 & 4 \\
$W_{2}$ & - & 3 \\
\hline \hline
\end{tabular}

The simulated $S_{11}$ and AR are shown in Fig. 3 for the single and dual spiral antennas. The single spiral slot antenna exhibits narrow impedance bandwidth $\left(\mathrm{S}_{11}<-10 \mathrm{~dB}\right)$ and $\mathrm{AR}$ bandwidth $(3 \mathrm{~dB})$. The dual spiral exhibits significantly improved impedance bandwidth for the low band and wider AR bandwidths for both bands.

\section{PARAMETRIC STUDIES}

The parametric study was made in order to evaluate the dual-band sensitivity to key parameters using the time domain solver in CST MWS. Other parameters were fixed as in Table 1.

\section{a) Widths of the $W_{1}$ and slots $W_{2}$}

The slot width plays a role in the antenna performance because it affects the input impedance. Fig. 4 shows the simulated $\mathrm{S}_{11}$ for various values of outer and inner slot widths $W_{1}$ and $W_{2}$. In this case, dual-frequency performance is optimum for slot widths of $3 \mathrm{~mm}$ or $4 \mathrm{~mm}$. Fig. 5 shows that the low frequency shifts upwards as $W_{2}$ is varied from $2 \mathrm{~mm}$ to $3 \mathrm{~mm}$. The frequency ratio $f_{2} / f_{1}$ can be tuned from 1.62 to 1.68 .

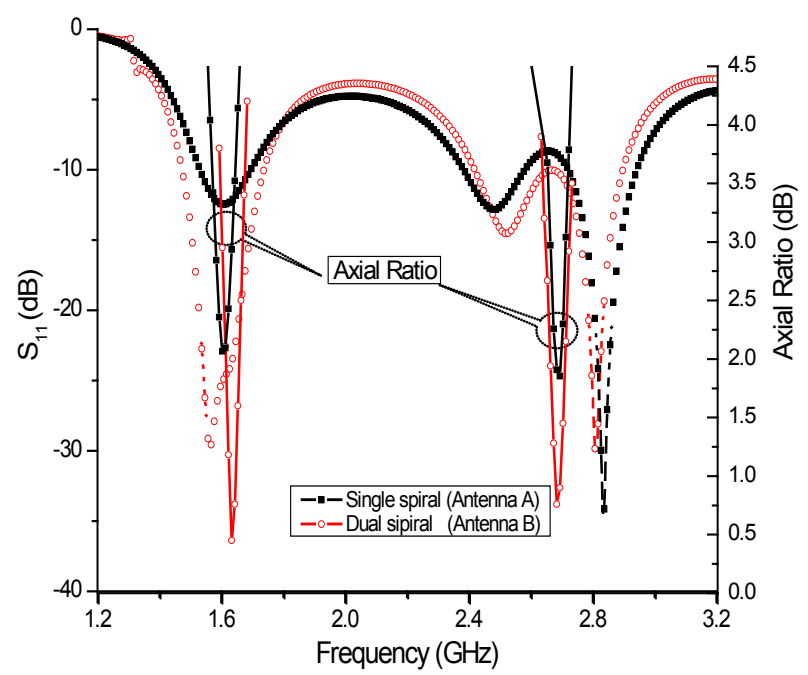

Fig. 3. Simulated $S_{11}$ and $A R$ for the single and dual spiral antennas

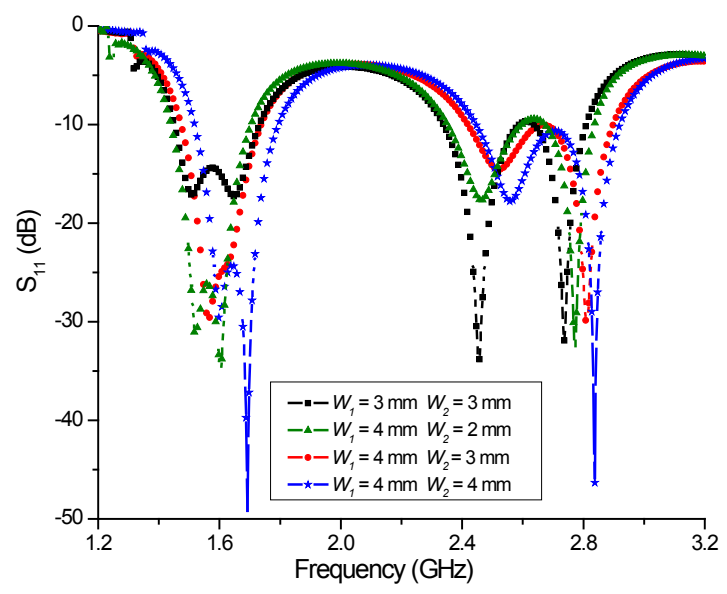

Fig. 4. Simulated $S_{11}$ for various slot widths

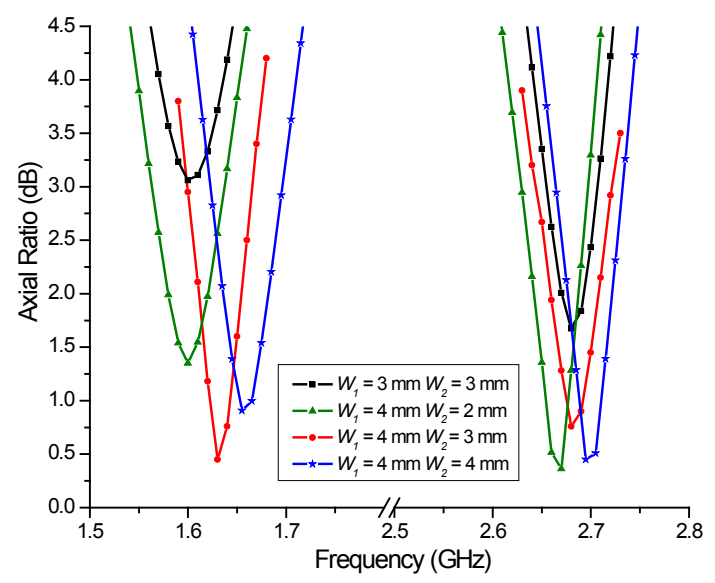

Fig. 5. Simulated axial ratio for various slot widths

\section{b) Coupling between inside and outside spiral slots}

The separation distance between inner and outer spirals slots can be used to control coupling and tailor the response of the antenna. Fig. 6 illustrates the simulated $S_{11}$ for different values of coupling separation $S_{c}$. As the separation decreases, coupling is stronger with improved matching and an upward shift in 
frequency for both bands. The low band frequency shifts upwards as the coupling distance $S_{c}$ is varied from $1 \mathrm{~mm}$ to $3 \mathrm{~mm}$. The frequency ratio of $f_{2} / f_{1}$ can be tuned from 1.60 to 1.70 as shown in Fig. 7. The antenna is sensitive to the length over which the spirals couple, denoted here by a coupling angle $\alpha$. Larger coupling angles improve matching for the low frequency whereas smaller angles improve the high frequency matching. The optimum angle for dual-band performance is $\alpha=90^{\circ}$.

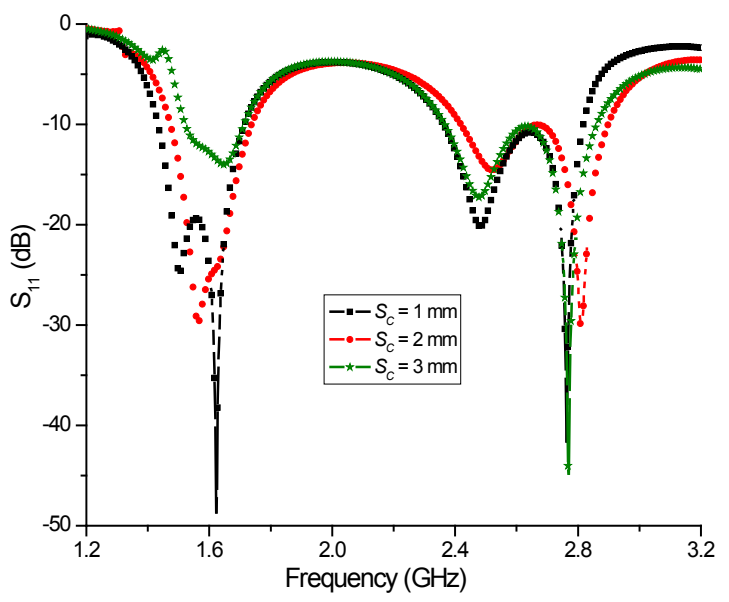

Fig. 6. Simulated $S_{11}$ for various slot separation distances

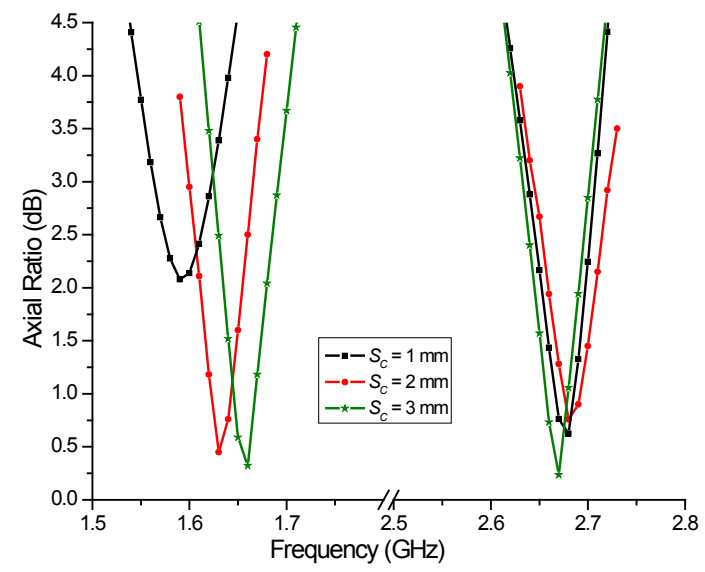

Fig. 7. Simulated axial ratio for various slot separation distances

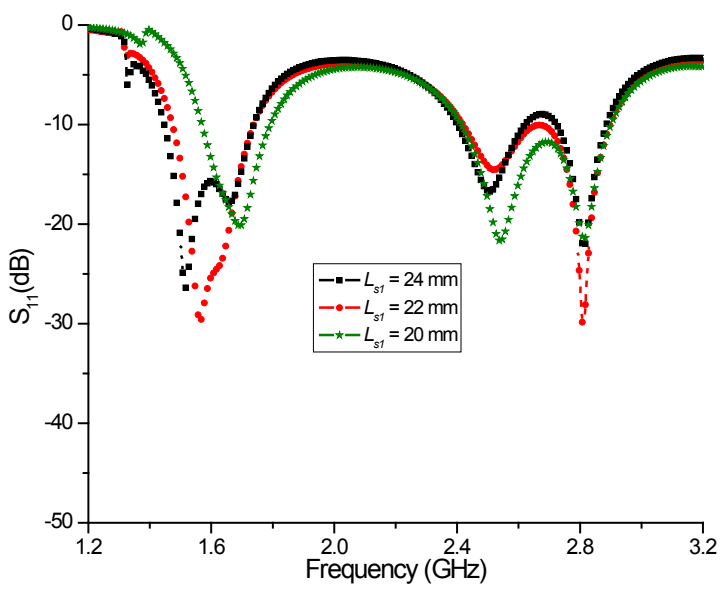

Fig. 8. Simulated $\mathrm{S}_{11}$ for various feedline lengths $L_{S I}$ c) The length of microstrip line $L_{s 1}$

The simulated $\mathrm{S}_{11}$ for different values of microstrip feedline length $L s_{1}$ is shown in Fig. 8. The low band shows greater sensitivity to this parameter and the impedance bandwidth decreases with decrease in line length. On other hand, the AR degrades as the length is increased as shown in Fig. 9. An appropriate feedline length is chosen to be $22 \mathrm{~mm}$ for best matching and AR bandwidth. For the dual spiral antenna, the microstrip feed couples to both inner and outer spiral slots. For shorter feedline lengths which couple only to the outer spiral, there is an upward shift in frequency and polarization becomes linear.

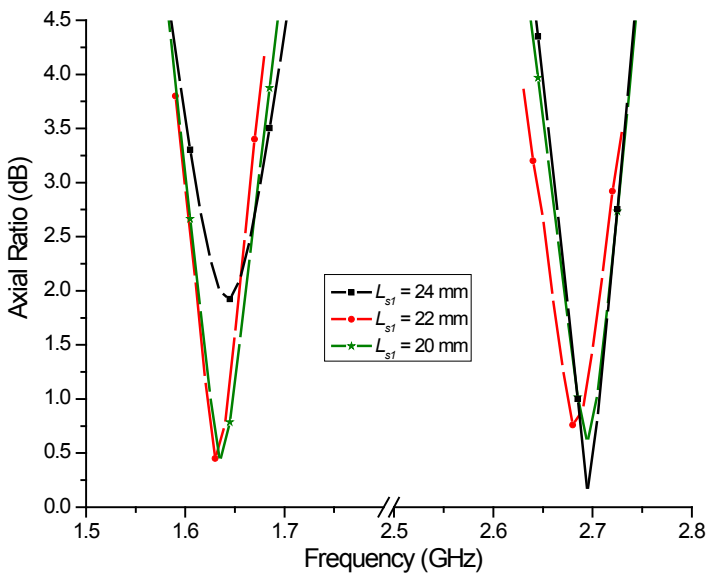

Fig. 9 Simulated axial ratio for various feedline lengths $L_{S I}$

\section{EXPERIMENTAL VERIFICATION}

The dual spiral slot antenna was fabricated on a Taconic RF35 laminate. Fig. 10 displays the measured and simulated $\mathrm{S}_{11}$ for the proposed antenna. The measurements show the impedance bandwidth to be $287 \mathrm{MHz} \quad(1.437 \mathrm{GHz}$ to $1.724 \mathrm{GHz}$ ) or about $18.2 \%$ with respect to the centre frequency of $1.580 \mathrm{GHz}$ for the first frequency band. For the second frequency band, the impedance bandwidth is $489 \mathrm{MHz}$ (2.418 GHz to $2.907 \mathrm{GHz}$ ) or about $18.4 \%$ with respect to the centre frequency of $2.663 \mathrm{GHz}$.

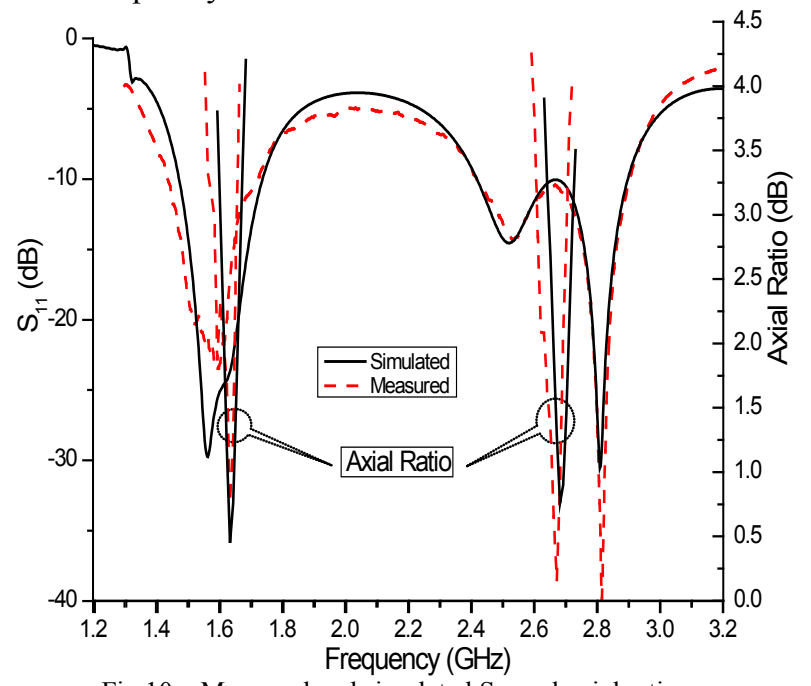

Fig 10. Measured and simulated $\mathrm{S}_{11}$ and axial ratio 
Furthermore, Fig. 10 illustrates the measured and simulated AR plotted against frequency, which is also in good agreement. The measured result shows the $3 \mathrm{~dB}$ AR bandwidth to be $72 \mathrm{MHz}(1.580 \mathrm{GHz}$ to $1.652 \mathrm{GHz})$ or about $4.45 \%$ with respect to $1.616 \mathrm{GHz}$ for the first band and $93 \mathrm{MHz}$ ( $2.609 \mathrm{GHz}$ to $2.702 \mathrm{GHz}$ ) or about $3.5 \%$ with respect to $2.655 \mathrm{GHz}$ for the second band.

Fig. 11 and Fig. 12 show the measured and simulated normalized radiation patterns at $1.64 \mathrm{GHz}$ and $2.68 \mathrm{GHz}$ for the $\mathrm{XoZ}$ and YoZ planes, respectively. It is shown that the cross-polar levels are below $20 \mathrm{~dB}$ in the direction of the main beam.

There is good agreement between the measured results and simulated results. The RHCP radiation pattern at $1.64 \mathrm{GHz}$ is symmetrical for the YoZ plane with a $3 \mathrm{~dB}$ beamwidth of $89^{\circ}$ and offset by $10^{\circ}$ for the XoZ plane with a beamwidth of $87^{\circ}$. For $2.68 \mathrm{GHz}$ the LHCP pattern is symmetrical with a beamwidth of $57^{\circ}$ for the $\mathrm{YoZ}$ plane and offset by $5^{\circ}$ with beamwidth of $61^{\circ}$ for the XoZ plane.

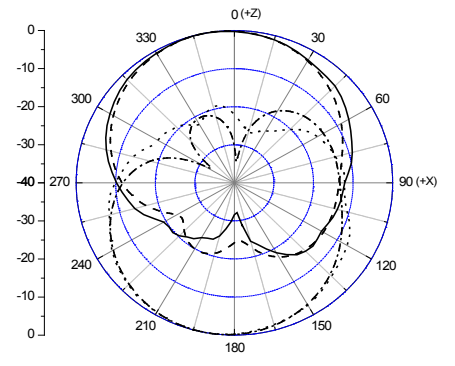

(a)

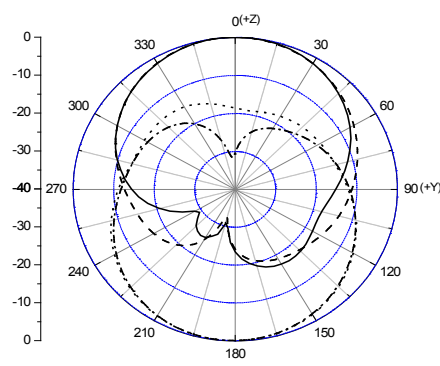

(b)
Fig 11. The measured and simulated radiation patterns at $1.64 \mathrm{GHz}$ (a) $\mathrm{XoZ}$ plane and (b) YoZ plane. Measured RHCP — Simulated RHCP . - Measured LHCP __. Simulated LHCP _...

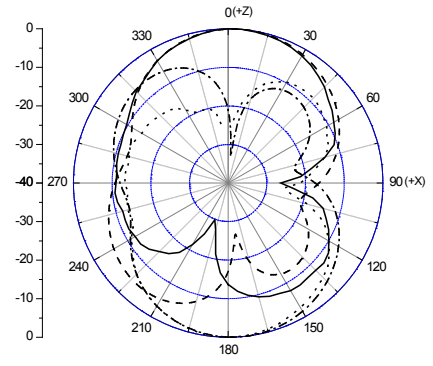

(a)

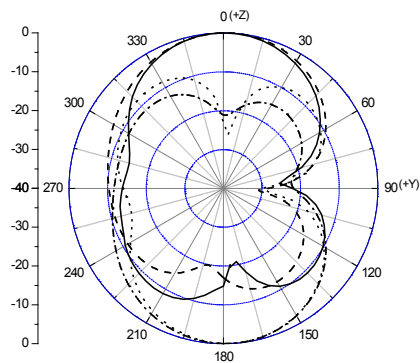

(b)
Fig 12. The measured and simulated radiation patterns at $2.68 \mathrm{GHz}$ (a) $\mathrm{XoZ}$ plane and (b) YoZ plane. Measured LHCP _ Simulated LHCP _. . . Measured RHCP Simulated RHCP ...

The measured gain values within the $3 \mathrm{~dB}$ AR bandwidths are from $3.9 \mathrm{dBic}$ to $4.4 \mathrm{dBic}$ for the low band and from $2.8 \mathrm{dBic}$ to $3.8 \mathrm{dBic}$ for the high band.

\section{CONCLUSION}

A novel dual circularly-polarized monofilar spiral slot antenna was modeled, fabricated and tested. The proposed antenna can achieve RHCP and LHCP for the low and high frequency bands, respectively. The antenna realizes an $18 \%$ impedance bandwidth for both bands and AR bandwidths of $4.5 \%$ and $3.5 \%$ with respect to the centre frequencies of $1616 \mathrm{MHz}$ and $2655 \mathrm{MHz}$, respectively.

\section{REFERENCES}

[1] H. W. Kwa, X. M. Qing, and Z. N. Chen, Broadband Single-Fed Single-Patch Circularly Polarized Antenna for UHF RFID Applications, IEEE Antennas and Propagation Society International Symposium, July 2008, pp.1-4.

[2] X. L. Bao, and M. J. Ammann, Compact Annular-Ring Embedded Circular Patch Antenna with a Cross-Slot Ground Plane for Circular Polarization, Electronics Letters, Vol. 42, No. 4, 2006, pp.192-193.

[3] F. Jou, J. W. Wu, and C. J. Wang, Novel Broadband Monopole Antennas With Dual-Band Circular Polarization, IEEE Transactions on Antennas and Propagation, Vol. 57, No. 4, 2009, pp.1027-1034.

[4] C. H. Chen, and E. K. N. Yung, Dual-Band Dual-Sense Circularly-Polarized CPW-Fed Slot Antenna With Two Spiral Slots Loaded, IEEE Transactions on Antennas and Propagation, Vol. 57, No. 6, 2009, pp. 1829-1833.

[5] X. L. Bao, M. J. Ammann, Dual-frequency Dual-sense Circularly-polarized Slot Antenna Fed by Microstrip Line, IEEE Transactions on Antennas and Propagation, 2008, Vol. 56, No.3, pp. 645-649.

[6] W. L. Curtis, Spiral Antennas, IRE Transactions on Antennas and Propagation, Vol. 8, May 1960, pp.298-306.

[7] C. J. Wang, and D. F. Hsu, A Frequency-Reduction Scheme for Spiral Slot Antenna, IEEE Antennas and Wireless Propagation Letters, Vol. 1, 2002, pp. 161- 164.

[8] R. T. Gloutak, and N. G. Alexopoulos, Two-Arm Eccentric Spiral Antenna, IEEE Transactions on Antennas and Propagation, Vol. 45, No. 4, 1997, pp.723-730.

[9] D. J. Muller, and K. Sarabandi, Design and Analysis of a 3-Arm Spiral Antenna, IEEE Transactions on Antennas and Propagation, Vol. 55, No. 2, 2007, pp.258-266.

[10] N. A. Stutzke, and D. S. Filipovic, Four-Arm 2nd- Mode Slot Spiral Antenna With Simple Single-Port Feed, IEEE Antennas and Wireless Propagation Letters, Vol. 4, 2005, pp. 213-216.

[11] J. M. Laheurte, Dual-Frequency Circularly Polarized Antennas Based on Stacked Monofilar Square Spirals, IEEE Transactions on Antennas and Propagation, Vol.51, No.3, 2003, pp.488-492.

[12] C. W. Jung, B. A. Cetiner, and F. De. Flaviis, A Single-Arm Circular Spiral Antenna with Inner/Outer Feed Circuitry for Changing Polarization and Beam Characteristics, 2003 IEEE Antennas and Propagation Society International Symposium, pp.474-477.

[13] H. Nakano, J. Eto, Y. Okabe, and J. Yamauchi, Tilted- and Axial-Beam Formation by a Single-Arm Rectangular Spiral Antenna With Compact Dielectric Substrate and Conducting Plane, IEEE Transactions on Antennas and Propagation, Vol. 50, No. 1, 2002, pp.17-23. 